\title{
PENSAMIENTOS SOBRE EL AFECTO
}

\author{
Yván Balabarca Cárdenas, $\mathrm{Mg}$. \\ Docente de la Facultad de Teología \\ Universidad Peruana Unión \\ yvanbalabarca@teologia.edu.pe
}

Mujeres de Jerusalén, si encuentran a mi amado, prométanme decirle que me estoy muriendo de amor

Cantares 5:8, DHH.

Fecha de recepción: Octubre 2014.

Fecha de aceptación y versión final: Diciembre 2014.

Más allá de la simple frase "me gusta él (ella)", es necesario conocer a la otra persona. Concebir y desarrollar el amor verdadero, es una necesidad de la vida.

Palabras clave: Relaciones humanas. 


\section{THOUGHTS ON AFFECTION}

O daughters of Jerusalem, if you find my beloved, that you tell him I am sick with love.

Song of Solomon 5:8, RSV.

\section{Abstract}

Beyond the simple phrase "I like him (her)," It is necessary in life to conceive and develop true love.

Keywords: Human Relations. 


\section{Introducción}

Estamos en una época en la que se ha teorizado demasiado el amor, y eso ha hecho que se viva en un mundo en el que se escribe sobre el tema, pero se ve menos la práctica del mismo. Pero el amor es real y vale la pena luchar por vivirlo, experimentándolo de manera auténtica. ${ }^{1}$

Es importante que las personas vivan el amor, de manera concreta y no solo de palabras. Quien es amor, de manera pura y suprema, es el mismo Dios. Se debe aceptar que Dios, que es amor, no es un ser solitario, sino que, debido a ello, vive en comunidad (la Trinidad) y que por la misma razón se deleita al tener una familia cósmica, la cual proclama por el universo que Él es amor. ${ }^{2}$

${ }^{1}$ Pablo A. Deiros, El amor es cosa seria (El Paso, Tx: Casa Bautista de Publicaciones, 1988), 5.

${ }^{2}$ Scott Hahn, Lo primero es el amor: descubre tu familia en la Iglesia y en la Tri-

\section{La fuente del amor}

Quien aspire a amar de verdad, tendrá que relacionarse con la fuente misma del amor, Dios. La comunión con el Señor a través de una vida de oración y el estudio de su sagrada voluntad en la Biblia, es indispensable en este proceso, además, compartir los hallazgos de fe con el resto de las personas. Eso es evidencia del amor. Pues el amor se basa en dar; busca el desarrollo -la salvación- de la persona amada.

El amor verdadero gira en torno a ciertas características señaladas por Pablo:

1 de Corintios 13:4 - 7 "El amor es sufrido, es benigno; el amor no tiene envidia, el amor no es jactancioso, no se envanece; no hace nada indebido, no busca lo suyo, no se irrita, no guarda rencor; no se goza de la injusticia, mas se goza de la verdad. Todo lo sufre, todo lo cree, todo lo espera, todo lo soporta”.

nidad (Madrid: Ediciones Rialp, 2006), 11. 


\section{El amor gira en torno a dar}

$\mathrm{El}$ amor, en resumen, gira en torno al dar todo. Vida, dinero, tiempo, regalos, actos de servicio, paciencia, esfuerzo... entre otras cosas, con el fin de beneficiar a quien es el o la depositaria (o) de los afectos. Pero si el amor solo da, y se encuentra con una persona que no sabe dar, sino solo recibir, entonces es un sistema incompleto. Aun Dios espera que sus hijos lo amen y lo obedezcan (Juan 14:15).

Una persona que ama verdaderamente no da para recibir, sin embargo, recibe, porque ama a otra persona que también desea dar. Esta es la ecuación del amor verdadero. Dos personas que desean dar y proyectarse al otro, por lo tanto, ambos reciben.

Esta es la clase de amor que hace que dos personas con pasados diferentes y hogares distantes, se unan y decidan envejecer juntos, y no solo en el aspecto sexual, sino llegar a comulgar en gustos, sueños, aficiones, acciones, hábitos, deseos, así como llegar a comunicarse, además de las palabras, con el idioma íntimo de los gestos.

Esta experiencia no necesariamente es siempre gratificante, ya que se construye en base a mucha paciencia, tolerancia, negación, dedicación y esfuerzo. Eso es amor. Una ecuación cuyo resultado es la igualdad en la unidad.

\section{Diferentes aspectos del amor}

En el idioma griego antiguo (koiné) hay varias palabras que designan diversos aspectos del amor, permítame revisar las siguientes:

Ágape: este es el amor de entrega, de sacrificio y su máximo exponente es Jesucristo. Él se entregó a sí mismo por usted. $\mathrm{Su}$ vida toda fue una vida de servicio y renuncia de sí mismo. Toda su vida fue marcada por la generosidad. ${ }^{3}$

${ }^{3}$ Pedro A. Larson, Principios de lide- 
Este amor, haciendo una aplicación netamente social, se manifiesta cuando una persona decide sacrificar horas de sueño por ayudar a su amigo, amada o cónyuge, en actos concretos como: ayudarle con un trabajo académico, buscar datos o conseguir material didáctico en la web, en su propio hogar; para luego ir al encuentro del ser amado, a su casa, con los materiales conseguidos, en el primer y segundo caso o en el tercer caso (casados), ayudarle a hacer dormir a sus niños si se despiertan por la noche.

Eso es amor ágape ejemplificado.

Eros: esta palabra no se encuentra en la Biblia y frecuentemente tiene una connotación negativa, ${ }^{4}$ sin embargo, es parte del proceso de atracción entre

razgo espiritual (Terrassa, Barcelona: Clie, 1998), 108, 109.

${ }^{4}$ Lewis A. Drummond, Amor (Grand Rapids, Michigan: Editorial Portavoz, 2004), 49, 50 . dos personas, aunque, claro está, no debe tener la primacía de la relación.

Filos: sobre este, se puede encontrar mucho material que, a más de uno, ha resultado empalagoso. Este es el amor entre padres e hijos. También puede darse entre pares, como entre hermanos o amigos. ${ }^{5}$

Para llegar a casarse, se necesita algo de cada uno de estos amores, unidos en uno solo llamado amor verdadero de pareja. El amor ágape que implica sacrificio, unido al amor eros que denota atracción física y el amor filos, que incluye camaradería, son los ingredientes necesarios, todos en equilibrio, claro está, para que una pareja emprenda el dulce camino de la vida en el estado matrimonial.
${ }^{5}$ Javier Sádaba, El amor y sus formas (Barcelona: Península, 2010), 111. 


\section{La madurez afectiva}

Este nivel de madurez afectiva se logra cuando se han superado los veinte años, como lo señala Elena G. de White:

"El joven, que aún no ha pasado los veinte años, es un pobre juez de la idoneidad de una persona tan joven como él para ser la compañera de su vida. Una vez que ha madurado su criterio, se contemplan atados uno a otro para siempre, y quizá sin condiciones para hacerse mutuamente felices. Entonces, en vez de tratar de sacar el mejor partido de su suerte, se hacen recriminaciones, la brecha se agranda hasta sentir completa indiferencia el uno hacia el otro. La palabra hogar no tiene nada de sagrado para ellos. Hasta su misma atmósfera está envenenada por palabras duras y amargos reproches." 6

${ }^{6}$ Elena G. de White, Mensajes para los jóvenes (Mountain View, Calif: Publicaciones Interamericanas, Pacific Press, 1979), 449.
Quiere decir, que el estado de noviazgo con menos riesgos se da luego de los veinte; pero encontramos a los adolecentes dando rienda suelta a sus afectos, conociendo a través de relaciones afectivas más allá de las meramente filiales. Me pregunto ¿es necesario estar de novio o novia para conocer a alguien?, ¿dónde quedó la grandeza de la amistad?, ¿dónde radica el apuro?

\section{El amor en la adolescencia}

Recordemos que la adolescencia es un estado de condición y proceso de crecimiento; es la etapa del desarrollo humano que marca el final de la niñez y crea los cimientos de la edad adulta. Se experimentan cambios interdependientes en las dimensiones biológicas, psicológicas y sociales. Se inicia aproximadamente entre los 9 y 13 años y finaliza cuando el individuo alcanza la madurez emocional y social, para asumir un rol de joven, según se defina en la cultura en la que vive. Es una etapa de plena expansión 
intelectual y cognitiva, de asimilación de experiencias positivas y evaluación de valores e ideales. $^{7}$

Este es un momento de grandes cambios a todo nivel, en el ser humano y, aunque algunos sugieran que es normal que los adolescentes exploren el tema del amor romántico, pues no es lo mejor, ya que están en la etapa de ganar madurez y ser amigos y amigas de diversos jóvenes y señoritas (Recordemos que la amistad es la "cantera" del noviazgo).

Los adolescentes, con su modelo de pensamiento, consideran que los adultos no se aman porque no quieren estar siempre juntos, no desean hacer lo mismo, no están de acuerdo en todo, y discuten; a diferencia de ellos que quieren estar todo el día juntos, confundiendo así el amor verdadero con el amor adolescente,

${ }^{7}$ Anameli Monroy, Salud y sexualidad en la adolescencia y juventud: guía práctica para padres y educadores (México, D.F.: Ed. Pax México, 2002), 11, 12. posesivo e inmaduro. Más de un adolescente piensa: "si me quieres, no hables con nadie, solo conmigo. No hagas nada con nadie, ni con tus padres, pasa el tiempo conmigo", denotando su inmadurez social. ${ }^{8}$

Incluso, puede llegar a mimetizar sus formas de amar, no con lo que es mejor, sino con sus experiencias previas, no necesariamente saludables, obtenidas de sus camaradas, parientes o tutores; y hasta lograr madurar, pueden desarrollar pensamientos como, por ejemplo: "las mujeres no aman de verdad (porque mi madre no me amó)" o "los hombres son peligrosos (porque mi padre lo fue)", entre otros. Es necesario que lleguen a un estado de madurez mental para poder romper el círculo que los puede enredar. ${ }^{9}$

${ }^{8}$ Maite Vallet, Cómo educar a nuestros adolescentes: un esfuerzo que merece la pena (Barcelona: Editorial Praxis, 2006), 170.

${ }^{9}$ Marie Lise Labonte, Hacia el amor verdadero (Barcelona: Ediciones Luciérnaga, 2010), 61. 
Llegar a disfrutar de manera saludable la adolescencia, y superarla como una etapa hermosa, es el requisito para llegar a la capacidad de amar, sin sombras del pasado, arrepentimientos del presente, ni miedos del futuro.

Si un adolescente solo se dejara llevar por el sentimiento, no estaría siendo razonable. Se necesita hacer un balance entre lo racional y lo emotivo.

\section{El manejo de las emociones}

También la inmadurez se evidencia en el mal manejo de las emociones, como resultado del término de una relación en la adolescencia. Lo que sucede es que la persona que se amaba provocaba que el cerebro generara feniletilaminas, catecolaminas, endorfinas y epinefrinas que hacían que el novio o novia se sintiera muy bien; pero cuando la persona ya no desea amar, las emociones que esas sustancias químicas generaban, no son satisfechas, produciéndose un estado similar a un sindrome de abstinencia.

Nacen deseos de buscar a quien ya no quiere amar. Entonces la persona, que fue dejada, usa algún medio de comunicación como el mensaje de texto, el internet, el teléfono para, de algún modo, comunicarse con el ser amado y así, poder menguar el dolor. Pero esto no es lo mejor.

La relación se terminó, se tendría que ser lo suficientemente maduro (a) para poder transitar las etapas que llevan el haber acabado una relación, siendo la primera, el llanto y la negación y es legítimo entristecerse porque hay dolor de por medio. Surgen preguntas como: ¿por qué a mí?, ¿Qué hice mal?

En segundo lugar viene la cólera o la ira, y aquí existe el peligro de hablar mal de la persona que una vez amó y que todavía se sigue añorando.

La tercera etapa es la etapa del regateo. La persona doliente se arrepiente de todas las cosas malas que dijo en la etapa de ira y acepta, de manera parcial, 
su situación y realidad. Trata de comprender lo que sucedió.

La cuarta etapa es la etapa de la aceptación que va acompañada de un dolor, generado por aceptar la ausencia de la persona que ama. Se inicia una etapa de silencio y apatía probable.

La quinta etapa es la etapa de la aceptación sanadora, es decir, se empiezan a restablecer afectos, empieza a hallarse el equilibrio emocional y la paz. Todo, poco a poco, vuelve a la calma y a la normalidad. ${ }^{10}$

Dicen los expertos que para 86 que haya una total recuperación del dolor, producido por haber terminado una relación de noviazgo, deben pasar 6 meses sin ningún tipo de comunicación, pasado aquel tiempo se podría retomar la relación de amistad con la persona con la que se terminó. Luego de 6 meses podrían llamarse amigos nuevamente, aunque esto último depende también del nivel

${ }^{10}$ Masza Maszlanka Chilerowicz, El duelo (Málaga: Vértice, 2007), 74 - 76. de madurez que hubo en la relación y en la experiencia resultante de esta etapa.

Esto también fortalece el consejo de que el noviazgo serio, maduro, con menos riesgos, se da luego de los veinte años, cuando la experiencia y la disposición de buscar relaciones interdependientes saludables generen relaciones afectivas más estables. Relaciones que equilibren y controlen el amor ágape, eros y filos; relaciones que trasciendan sobre la inestabilidad generada por el coctel hormonal que se libera en el organismo durante la adolescencia.

\section{Conclusión}

Es necesario orientar a dos grupos con urgencia: a los adolescentes, en tópicos de manejo del tiempo libre, habilidades sociales saludables e higiene, y orientación sexual; y, a los jóvenes, en tópicos de interdependencia saludable y habilidades para proyectarse hacia el sexo opuesto para construir relaciones afectivas funcionales. 